\title{
Further Evidence for Genetic Heterogeneity in Familial Hemophagocytic Lymphohistiocytosis (FHLH)
}

\author{
GAIL E. GRAHAM, LISA M. GRAHAM, PETER J. BRIDGE, LINDA D. MACLAREN, \\ JOHANNES E.A. WOLFF, MAX J. COPPES, AND R. MAARTEN EGELER \\ Departments of Medical Genetics [G.E.G., L.M.G., P.J.B., L.D.M.], Oncology [J.E.A.W., M.J.C., R.M.E.], \\ and Pediatrics [J.E.A.W., M.J.C., R.M.E.], Alberta Children's Hospital and University of Calgary, \\ Calgary, Alberta T2T 5C7, Canada
}

\begin{abstract}
Familial hemophagocytic lymphohistiocytosis (FHLH; MIM \#267700) is an autosomal recessive disorder of immune regulation characterized by fever, hepatosplenomegaly, and cytopenia that is fatal without bone marrow transplantation. Recent studies have suggested the existence of FHLH loci at 9q21.3-22 and 10q21-22 in Asian and European/African/Australian families, respectively. We studied two unrelated Canadian families in which first cousins were affected with FHLH. In an effort to localize the causative gene, we completed a genome-wide screen for homozygosity by descent by using an automated system to genotype 400 highly polymorphic dinucleotide repeat markers covering the genome with an average resolution of 10 centiMorgans (cM). We identified a total of three candidate loci that met the combined criteria for homozygosity by descent in one family and shared maternal alleles in the other family. One of these, D9S1690, had a cytogenetic localization (9q22.33) proximal to a previously reported inversion of chromosome 9 in an FHLH patient. However, additional closely linked flanking markers within $1-2 \mathrm{cM}$ of all three candidates did not conform to the
\end{abstract}

ABSTRACT

criteria for linkage in either family. Similarly, we excluded the linked 9q21.3-q22 and 10q21-22 regions recently reported in Asian and European/African/Australian families, respectively. The two families were then analyzed independently to encompass the possibility that they were segregating separate genes. Six additional candidate loci were identified on the basis of homozygosity for the same allele in all affected members of one family, but further analysis of closely linked flanking markers did not demonstrate similar homozygosity. Our data provide further evidence of genetic heterogeneity in FHLH and suggest the existence of at least a third locus for this disease. (Pediatr Res 48: 227-232, 2000)

\[ \text { Abbreviations } \]
FHLH, familial hemophagocytic lymphohistiocytosis
cM, centiMorgan
NK, natural killer cells
YAC, yeast artificial chromosome
EBV, Epstein-Barr virus

The term histiocytosis identifies a group of disorders that have in common the proliferation and accumulation of macrophages and/or dendritic cells (1). Familial hemophagocytic lymphohistiocytosis demonstrates the typical pattern of autosomal recessive inheritance with unaffected parents having one or more affected children. A genetic etiology is accepted on the basis of sibling clustering, a high rate of consanguinity among the parents of affected individuals, concordance of the phenotype in monozygotic twins, and the results of segregation analysis (2). Consequently, FHLH has been recognized as an

Received September 15, 1999; accepted March 1, 2000.

Correspondence and reprint requests: Gail E. Graham, M.D., Department of Medical Genetics, Alberta Children's Hospital, 1820 Richmond Road SW, Calgary, Alberta T2T 5C7, Canada.

Supported by grants from the Alberta Children's Hospital Research Foundation and the Histiocytosis Associations of Canada and America. Dr. M.J. Coppes is a Clinical Investigator of the Alberta Heritage Foundation for Medical Research. autosomal recessive condition in the compendium of single gene disorders known as Online Mendelian Inheritance in Man (3).

Despite recognition that FHLH is an inherited disorder, the diagnosis is difficult and often not made until a second affected child is born into a family. When we embarked on this study, the responsible gene(s) had not been localized, isolated, or characterized. Consequently, there was no carrier or prenatal testing available to those at risk of having an affected child. During the course of this study, two reports localizing putative FHLH genes in Asian (9q21.3-22) and European/African/ Australian (10q21-22) families were published (4, 5). Recently, Stepp et al. (6) demonstrated that the chromosome 10q21 locus for FHLH is PRF1, a gene encoding the protein perforin, known to be an important mediator of lymphocyte cytotoxicity. They found PRF1 mutations in eight patients, all of whom previously mapped to this locus by linkage analysis. 
The only constitutional chromosome rearrangement offering an additional clue to the localization of FHLH genes was a pericentromeric inversion of chromosome 9 with break points at $9 \mathrm{p} 23$ and $9 \mathrm{q} 31$ in an infant with FHLH (7). The authors of this report speculated that the patient may have inherited one FHLH mutation from a carrier parent, with disruption of the second locus by the inversion. However, coexistence of the inversion with FHLH in this patient could also have been coincidental.

The objective of the current study was to identify candidate regions on which to focus future efforts to localize and characterize the defect causing FHLH.

\section{METHODS}

Families. We studied two Canadian kindreds in which first cousins were affected with FHLH according to the diagnostic criteria proposed by the FHLH Study Group of the Histiocyte Society (8). These families were of Anglo-Saxon (English and Irish) origins. The Newfoundland family (kindred 1) consisted of three affected cousins, two of whom are alive (Fig. 1). The diagnosis of FHLH was confirmed by autopsy in the third. These three affected children were born to sisters. The fathers of these children have their origins in a small area of the province and are thought to be distantly related to each other as well as to their wives. All three children developed cytopenia and hepatosplenomegaly with neurologic symptoms in their first year of life. Histologic examination of bone marrow

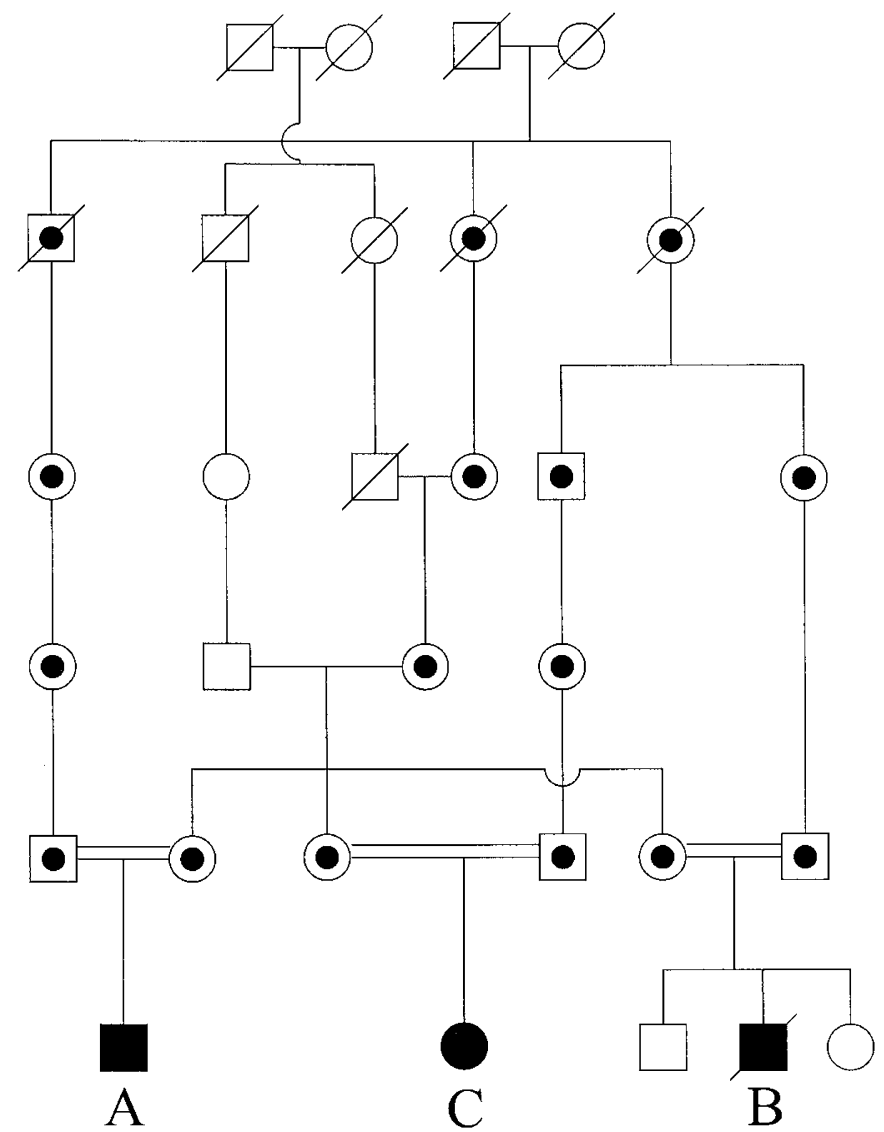

Figure 1. The Newfoundland family consisting of three affected first cousins born to consanguineous parents. Carrier status is inferred. and/or liver biopsy specimens demonstrated hemophagocytosis. After induction chemotherapy, patient A was treated intermittently with a maintenance regimen of cyclosporin A, corticosteroids, and intrathecal methotrexate until he received an unrelated bone marrow donor transplant at the age of 14 . He is currently $15 \mathrm{y}$ of age and his condition is stable without any signs of FHLH. Patient $C$ followed a similar clinical course and at the age of 11 remains on the maintenance regimen. She is currently being considered for an unrelated bone marrow donor transplant. She is developmentally delayed and is being treated for hypoparathyroidism in addition to FHLH. Patient B was the first child diagnosed in the family, and he died at the age of 9 mo.

The Nova Scotia family (kindred 2) consisted of two cousins affected with autopsy-confirmed FHLH who were also born to sisters (Fig. 2). The fathers of the affected children are not known to be related to the mothers or to each other. These two children had a classic early-onset and rapidly fatal clinical course. Patient E was diagnosed before 6 mo of age and died at 8 mo. Her cousin, patient $\mathrm{D}$, was diagnosed at 2 mo of age and died at $32 \mathrm{mo}$.

With informed consent and institutional ethics approval, we obtained skin biopsies for cultured fibroblasts from the two living affected children and pathologic tissue specimens from the three deceased children. In lieu of blood, skin biopsies were taken from the living children to ensure that their DNA would not be contaminated by their previous transfusions. We also obtained peripheral blood samples from all 10 parents. Genomic DNA was extracted from blood and tissue samples by standard methods (9).

Genotyping. The fact that the parents of the affected children in kindred 1 and the mothers of the affected children in kindred 2 were related, suggested that a common (healthy) ancestor must have carried a single copy of an altered FHLH gene in each family. In kindred 1 , the altered gene would have segregated independently through the various branches of the pedigree, and been inherited by all six parents. (The presence of a second normal copy of the gene in each of them would have

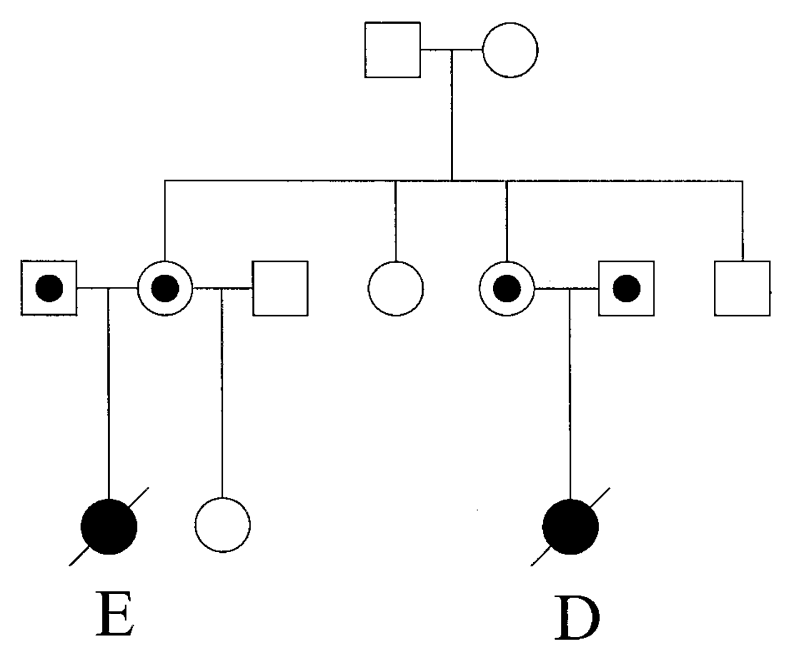

Figure 2. The Nova Scotia family consisting of two affected first cousins. The fathers of these children are not known to be related to their spouses or each other. 
prevented them from developing this recessive condition; hence, they would have been healthy carriers.) FHLH would have resulted when their children inherited two altered copies of the gene, one from each parent. A similar logic could be used for kindred 2, the primary difference being that only the mothers were assumed to have a common ancestor.

When the altered genes that are present in each of the affected children are derived from a common ancestor, a specific strategy can be used to find polymorphic markers that are in close proximity to the gene. The rationale is that any polymorphic marker that is close enough to the causative gene to be of interest will demonstrate homozygosity by descent. This is defined as the presence of identical alleles at a given marker locus in each of the affected individuals in a family.

We embarked on a search for a closely linked marker locus by using a commercial multiplex PCR genotyping system (Prism Linkage Mapping Set version 2, Perkin Elmer Applied Biosystems, Inc.) capable of typing 400 highly polymorphic markers located at an average interval of $10 \mathrm{cM}$ throughout the genome. Using this system and an ABI 377 automated sequencer with Genescan 2.1 and Genotyper 2.0 analysis software, we genotyped all 15 individuals (five affected children and 10 parents) for the $400 \mathrm{ABI}$ markers.

We performed simultaneous parental genotyping to identify shared maternal alleles in the Nova Scotia family as well as to confirm paternity and exclude sample mix-up in all cases. For the small number of markers in which amplification of the child's sample was suboptimal, the availability of parental genotypes also allowed us to infer the child's genotype and/or rule out homozygosity by descent.

Candidate loci were selected based on the presence of alleles that were homozygous and identical in all three affected children from the Newfoundland family. In the Nova Scotia family, any marker demonstrating shared maternal alleles in the two affected children was considered a candidate. Thirty-four additional dinucleotide PCR markers not included in the ABI kit and flanking promising candidate loci were amplified and genotyped for all individuals. The additional markers were selected from the summary maps available from The Genetic Location Database at the Wessex Human Genetics Institute (http://cedar.genetics.soton.ac.uk) (10), and primer sequences were located in the Genome Database (http://gdbwww.gdb.org). Fluorescent end-labeled primers were amplified in $15-\mu \mathrm{L}$ reactions with $10 \mathrm{mM}$ Tris- $\mathrm{HCl} \mathrm{pH} 8.3,50 \mathrm{mM} \mathrm{KCl}, 250 \mu \mathrm{M}$ dNTP, $0.33 \mu \mathrm{M}$ primers, $0.75 \mathrm{U}$ of AmpliTaq Gold (PerkinElmer), $50 \mathrm{ng}$ of genomic DNA, and $\mathrm{MgCl}_{2}$ optimized for each primer set at a concentration between 1.5 and $3.5 \mathrm{mM}$. Amplification was performed in an ABI 9600 thermocycler. DNA strands were denatured at $95^{\circ} \mathrm{C}$ for $12 \mathrm{~min}$ and subjected to 10 amplification cycles consisting of $95^{\circ} \mathrm{C}$ for $15 \mathrm{~s}, 52-58^{\circ} \mathrm{C}$ for $15 \mathrm{~s}$, and $72^{\circ} \mathrm{C}$ for $30 \mathrm{~s}$. This was followed by 24 amplification cycles consisting of $89^{\circ} \mathrm{C}$ for $15 \mathrm{~s}, 52-58^{\circ} \mathrm{C}$ for $15 \mathrm{~s}$, and $72^{\circ} \mathrm{C}$ for $30 \mathrm{~s}$, with a final extension at $72^{\circ} \mathrm{C}$ for $30 \mathrm{~min}$. Products were run on $4.25 \%$ polyacrylamide gel on an ABI 377 autosequencer and analyzed with GeneScan 2.1 and Genotyper 2.0 software as for the linkage kit markers.

\section{RESULTS}

In our initial genome scan, we assumed a common locus and combined the two families to maximize the power of the analysis. All 400 paternal genotypes were consistent with stated paternity for each of the five affected children, ruling out nonpaternity with a probability of error of less than $10^{-99}$. We identified a total of three candidate loci that met the combined criteria for homozygosity by descent in kindred 1 and shared maternal alleles in kindred 2 (boldface in Tables 1, 2, and 3). One of these, D9S1690, had a cytogenetic localization $(9 \mathrm{q} 22.33)$ proximal to one of the break points $(9 \mathrm{q} 31)$ of a previously reported inversion in an FHLH patient (5). We genotyped a total of 17 additional closely linked flanking markers mapping within $1-2 \mathrm{cM}$ of either side of all three candidates. These markers were chosen from the Genetic Location Database (10) for their close proximity to the candidates, though it should be acknowledged that these marker localizations are based on a small number of families and may not be as precise as stated. None of the haplotypes from these additional markers demonstrated a pattern suggestive of homozygosity by descent despite the very small recombination distance between the markers and the candidates (Tables 1-3). In addition, the observed

Table 1. Genotypes for candidate locus D9S1690 and flanking markers

\begin{tabular}{|c|c|c|c|c|c|c|c|}
\hline \multirow[b]{2}{*}{ Marker } & \multirow[b]{2}{*}{$\begin{array}{l}\text { Cytogenetic } \\
\text { localization }\end{array}$} & \multirow{2}{*}{$\begin{array}{l}\text { Genetic } \\
\text { distance } \\
(\mathrm{cM}) \dagger\end{array}$} & \multicolumn{3}{|c|}{ Kindred 1 patients* } & \multicolumn{2}{|c|}{ Kindred 2 patients* } \\
\hline & & & $\begin{array}{c}\mathrm{A} \\
\text { (mat/pat) } \ddagger\end{array}$ & $\begin{array}{c}\text { B } \\
\text { (mat/pat) }\end{array}$ & $\begin{array}{c}\mathrm{C} \\
\text { (mat/pat) }\end{array}$ & $\begin{array}{c}\mathrm{D} \\
\text { (mat) }\end{array}$ & $\begin{array}{c}\mathrm{E} \\
\text { (mat) }\end{array}$ \\
\hline D9S272 & $9 \mathrm{q} 22.32$ & 1.91 & $202 / 204$ & $206 / 204$ & $200 / 200$ & 206 & 206 \\
\hline D9S176 & $9 q 22.33$ & 1.24 & $130+140 \S$ & $132 / 134$ & $130 / 138$ & 136 & 130 \\
\hline D9S1857 & $9 q 22.33$ & 1.08 & $264 / 268$ & $264 / 270$ & $264 / 260$ & 268 & 264 \\
\hline D9S1690 & $9 q 22.33$ & 0.00 & $231 / 231$ & $231 / 231$ & $231 / 231$ & 231 & 231 \\
\hline D9S750 & $9 q 31.1$ & 1.64 & $267 / 269$ & $269 / 261$ & $255 / 271$ & 251 & 263 \\
\hline D9S109 & $9 q 31.1$ & 1.78 & $224 / 218$ & $220 / 220$ & $-\pi / 220$ & 224 & -9 \\
\hline D9S277 & $9 \mathrm{q} 31.1$ & 3.26 & $198 / 172$ & $182 / 166$ & $-\mathbf{q}-\mathbf{q}$ & 196 & -9 \\
\hline
\end{tabular}

* A-E refer to the affected children in Figures 1 and 2.

$\dagger$ Averaged from male and female recombination distances in The Genetic Location Database at the Wessex Human Genetics Institute (http:// cedar.genetics.soton.ac.uk) (Ref. 9) or taken from Prism Linkage Mapping Set version 2, Perkin Elmer Applied Biosystems, Inc.

† Mat and pat designate maternally and paternally derived alleles.

$\S+$ Designates that maternal and paternal alleles could not be distinguished.

I - Designates failed PCR or uninformative genotypes; parental alleles rule out locus as candidate.

Bolded alleles meet criteria for homozygosity in kindred 1 or 2. 
Table 2. Genotypes for candidate locus D14S276 and flanking markers

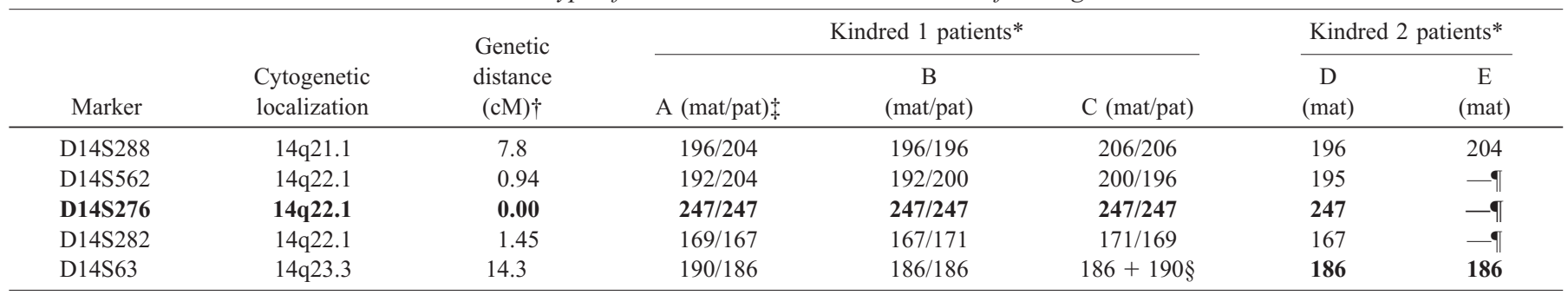

See Table 1 for footnotes.

Table 3. Genotypes for candidate locus D19S414 and flanking markers

\begin{tabular}{|c|c|c|c|c|c|c|c|}
\hline \multirow[b]{2}{*}{ Marker } & \multirow[b]{2}{*}{$\begin{array}{l}\text { Cytogenetic } \\
\text { localization }\end{array}$} & \multirow{2}{*}{$\begin{array}{c}\text { Genetic } \\
\text { distance } \\
(\mathrm{cM}) \dagger\end{array}$} & \multicolumn{3}{|c|}{ Kindred 1 patients* } & \multicolumn{2}{|c|}{ Kindred 2 patients* } \\
\hline & & & $\begin{array}{c}\mathrm{A} \\
\text { (mat/pat) } \ddagger\end{array}$ & $\begin{array}{c}\text { B } \\
\text { (mat/pat) }\end{array}$ & $\begin{array}{c}\mathrm{C} \\
\text { (mat/pat) }\end{array}$ & $\begin{array}{c}\mathrm{D} \\
\text { (mat) }\end{array}$ & $\begin{array}{c}\mathrm{E} \\
\text { (mat) }\end{array}$ \\
\hline D19S226 & $19 \mathrm{p} 13.13$ & 12.6 & $252 / 242$ & $251 / 261$ & $254 / 258$ & 252 & 252 \\
\hline D19S882 & $19 q 12$ & 0.88 & $269 / 281$ & $269 / 281$ & $281 / 277$ & 281 & 281 \\
\hline D19S414 & $19 q 12$ & 0.00 & $189 / 189$ & $189 / 189$ & $189 / 189$ & 189 & 189 \\
\hline D19S245 & $19 \mathrm{q} 13.11$ & 2.00 & $194 / 202$ & $194 / 198$ & $206 / 206$ & 202 & 202 \\
\hline D19S220 & $19 q 13.13$ & 7.90 & $280 / 286$ & $280 / 284$ & $282 / 280$ & 280 & 274 \\
\hline
\end{tabular}

See Table 1 for footnotes.

marker patterns did not conform to homozygosity by descent when a small number of recombination events were inferred.

The two families were then analyzed independently to encompass the possibility that they were segregating different genes. Kindred 2, consisting of affected first cousins born to sisters, was of limited use in the independent analysis because the only criterion for identification of candidate loci was the demonstration of shared maternal alleles. First cousins share, on average, one eighth of their genes; therefore, at least one eighth of the tested markers (approximately 50 of the 400) would be expected to meet these criteria on the basis of chance alone. In fact, a total of 112 markers demonstrated shared maternal alleles in kindred 2, and an additional 17 markers may have been shared but were not fully informative. Linkage analysis to further evaluate these markers as candidates was not possible because of the paucity of unaffected children in each of the two sibships. These would be considered candidate markers for future exploration in any additionally ascertained families that are suitable for homozygosity by descent or traditional linkage approaches.

Instead, we focused on kindred 1 with three affected first cousins and consanguineous parents. Six additional candidate loci were identified on the basis of shared homozygous alleles in this family (D1S2697, D3S1278, D3S1565, D8S549,
D9S1826, and D16S516), but further analysis of closely linked flanking markers did not demonstrate this pattern (data not shown). Once again, the observed marker alleles did not conform to homozygosity by descent even if a small number of recombination events were inferred.

During the course of this study, two reports localizing the FHLH gene were published $(4,5)$. We examined these 9q21.3q22 and 10q21-22 regions in both of our families by using the same markers with which linkage was established in these reports (D9S175, D9S1867, D9S264, D9S167, D9S152, D9S1877, D9S1865, D9S1790, D9S283, D10S537, D10S1650, D10S556, D10S206, and D10S1686). D9S175 and D9S283 had previously been tested as part of the ABI Prism Linkage Set. Our results allowed us to eliminate these regions as candidates on the basis that none of these markers produced a pattern consistent with homozygosity by descent in our families (Tables 4 and 5).

\section{DISCUSSION}

FHLH is the most common HLH seen in infancy and childhood, with an estimated incidence of 0.12 cases per 100,000 children per year (11). It has been reported from all continents and from many ethnic groups. An increased inci-

Table 4. Genotypes for candidate locus $9 q 21.3-9 q 22$ and flanking markers

\begin{tabular}{|c|c|c|c|c|c|c|c|}
\hline \multirow[b]{2}{*}{ Marker } & \multirow[b]{2}{*}{$\begin{array}{l}\text { Cytogenetic } \\
\text { localization }\end{array}$} & \multirow{2}{*}{$\begin{array}{c}\text { Genetic } \\
\text { distance } \\
(\mathrm{cM}) \dagger\end{array}$} & \multicolumn{3}{|c|}{ Kindred 1 patients* } & \multicolumn{2}{|c|}{ Kindred 2 patients* } \\
\hline & & & $\begin{array}{c}\mathrm{A} \\
(\mathrm{mat} / \mathrm{pat}) \ddagger\end{array}$ & $\begin{array}{c}\text { B } \\
\text { (mat/pat) }\end{array}$ & $\begin{array}{c}\mathrm{C} \\
\text { (mat/pat) }\end{array}$ & $\begin{array}{c}\mathrm{D} \\
\text { (mat) }\end{array}$ & $\begin{array}{c}\mathrm{E} \\
(\mathrm{mat})\end{array}$ \\
\hline D9S264 & $9 q 22.1$ & 2.23 & $153 / 166$ & $152 / 152$ & $164+166 \S$ & 164 & 166 \\
\hline D9S167 & $9 \mathrm{q} 22.1$ & 0.69 & $316 / 313$ & $318 / 316$ & $320 / 318$ & 325 & 323 \\
\hline D9S152 & $9 \mathrm{q} 22.1$ & 0.00 & $-1-9$ & $127 / 127$ & $129 / 133$ & 127 & 125 \\
\hline D9S1877 & $9 \mathrm{q} 22.1$ & 0.59 & $125 / 125$ & $125 / 123$ & $123 / 127$ & 123 & 123 \\
\hline
\end{tabular}

See Table 1 for footnotes. 
Table 5. Genotypes for candidate locus 10q22.2-10q22.3 and flanking markers

\begin{tabular}{|c|c|c|c|c|c|c|c|}
\hline \multirow[b]{2}{*}{ Marker } & \multirow[b]{2}{*}{$\begin{array}{l}\text { Cytogenetic } \\
\text { localization }\end{array}$} & \multirow{2}{*}{$\begin{array}{c}\text { Genetic } \\
\text { distance } \\
(\mathrm{cM}) \dagger\end{array}$} & \multicolumn{3}{|c|}{ Kindred 1 patients* } & \multicolumn{2}{|c|}{ Kindred 2 patients* } \\
\hline & & & $\begin{array}{c}\mathrm{A} \\
(\mathrm{mat} / \mathrm{pat})+\end{array}$ & $\begin{array}{c}\mathrm{B} \\
\text { (mat/pat) }\end{array}$ & $\begin{array}{c}\mathrm{C} \\
\text { (mat/pat) }\end{array}$ & $\begin{array}{c}\mathrm{D} \\
\text { (mat) }\end{array}$ & $\begin{array}{c}\mathrm{E} \\
\text { (mat) }\end{array}$ \\
\hline D10S1650 & $10 \mathrm{q} 22.2$ & 0.00 & $134 / 138$ & $138 / 118$ & $138 / 144$ & 134 & 134 \\
\hline D10S556 & $10 \mathrm{q} 22.2$ & 1.10 & $191 / 195$ & $197 / 197$ & $197 / 193$ & 197 & 197 \\
\hline D10S206 & $10 \mathrm{q} 22.2$ & 0.84 & $265 / 265$ & $255+265 \S$ & $265 / 265$ & 265 & 262 \\
\hline
\end{tabular}

See Table 1 for footnotes.

dence has been noted in ethnic groups in which consanguineous matings are part of the cultural tradition (2). Although 70\% of patients experience onset of symptoms in the first year of life, the disease may present itself as late as the eighth year of life. Within a given family, a tendency toward similar ages of onset has been reported (12).

The signs and symptoms may vary widely, from intermittent fever, pronounced hepatosplenomegaly, and bone marrow suppression to progressive cerebromeningeal symptoms. Hypertriglyceridemia and coagulation abnormalities, particularly hypofibrinogenemia, are common findings. Histopathologically, FHLH is characterized by a nonmalignant mixed lymphohistiocytic accumulation in the monophagocytic system. Finally, most patients have low or absent NK activity and T-cell cytotoxicity (13).

Without treatment, FHLH is usually rapidly fatal with a median survival of approximately 2 mo (14). Although the combination of steroids and epipodophyllotoxins prolongs survival (15), hematopoietic stem cell transplantation remains the only cure (16). Localization of the gene for FHLH would be helpful in the early identification of at-risk siblings in families with a previously affected child. In addition, it would represent the first step toward isolation and characterization of the gene and its protein product.

Using the homozygosity-by-descent strategy in these two unique Canadian families, we completed a genome screen at an average resolution of $10 \mathrm{cM}$. This technique has been used to localize a wide variety of genes and has proven successful for other conditions in which DNA from as few as four (17) or five (18) affected individuals was available. In our combined and independent analyses, we detected a total of nine candidate loci; however, closely linked and highly polymorphic dinucleotide repeat markers flanking each candidate did not demonstrate a similar pattern of identical alleles. This suggests that the original observations were due to chance alone.

There are at least four explanations for our failure to identify a candidate locus by use of this strategy. The first and most likely is that the gene of interest lies in an interval between the $\mathrm{ABI}$ markers. These are spaced at average distances of $10 \mathrm{cM}$ but range from as little as $2.4 \mathrm{cM}$ to as large as $24.1 \mathrm{cM}$. If the gene is located in the center of one of the large intervals, recombination between the gene and one or more flanking markers may have taken place. Assuming a common founder for the carrier haplotype in the first generation of kindred 1, there have been a total of 22 meioses between the founder and the three affected cousins in the fifth generation. Each of these meioses would be associated with a small opportunity for recombination, and this was a possibility that we acknowledged at the outset of the study.

Inaccurate pedigree information represents the second possible source of error. Unfortunately, there is no population or church registry by which we were able to confirm the family relationships reported to us by the parents of kindred 1 . We have reexamined the data to consider the possibility that one of the fathers was unrelated to the family (described below).

The third explanation is that of inaccurate diagnosis: namely, that our patients did not have primary (familial) hemophagocytic lymphohistiocytosis. Recently, Janka et al. (19) reviewed the literature with respect to secondary (infection- and malignancy-associated) hemophagocytic syndromes. Over a period of 16 y (1979-1995), 219 children ranging from newborns to $18 \mathrm{y}$ of age had been described in the literature. A triggering organism was identified in 163 of 219 cases. In approximately $75 \%$, EBV infection was the cause. Other viruses identified included human herpes virus 6 , cytomegalovirus, adenovirus, parvovirus, and Varicella zoster virus. Herpes simplex virus, Q-fever virus, and measles virus were found in a few cases. A bacterial infection in approximately $7 \%$ and a fungal or a parasitic infection in 1 to $2 \%$ led to the hemophagocytic syndrome. These causes were all excluded in the patients described here.

All of our affected cousins met the existing criteria for the diagnosis of FHLH (8), and, in three of the five individuals, the diagnosis was confirmed by autopsy findings. Of potential relevance, however, are the unusual clinical courses in the two living affected cousins in kindred 1, patients $\mathrm{A}$ and $\mathrm{C}$, who are surviving at 15 and $11 \mathrm{y}$ of age. Because the presence of a different disease allele from the father of child B may explain the different course in this child, we reexamined the data from kindred 1, making the assumption that the father of patient $\mathrm{B}$ was unrelated to the family. Candidate markers in this reanalysis had to demonstrate identical alleles in patients $\mathrm{A}$ and $\mathrm{C}$ and a shared maternal allele in patient B. This analysis yielded eight additional loci on six different chromosomes. Three of these eight loci were on the same chromosome, but none of them contiguous or in close proximity, and the intervening loci did not conform to these criteria. In addition, none of the eight loci demonstrated shared maternal alleles in kindred 2. An alternate and more likely explanation for the more severe course in patient B is that he was the first affected individual in his family. The diagnosis was not made as quickly as it was in his cousins, who were the beneficiaries of very early treatment.

A fourth possible source of error is that the disease in either or both families is the result of digenic inheritance. This 
explanation would require that the parents of one or more of the affected children were carriers of mutations in different FHLH genes. Although possible, this seems unlikely, particularly in kindred 1 in which parental consanguinity would favor a single founding mutation.

Previous reports have localized putative genes for FHLH to the long arms of chromosome 9 and 10 in families of Asian and mixed European/African/Australian origins $(4,5)$. The chromosome-10 locus is now known to encode the perforin protein, and both nonsense and missense mutations in the PRF1 gene have been demonstrated in eight FHLH patients (6). All of these patients were from families that had previously been linked to $10 \mathrm{q} 21-22$. The newly revised localization of the PRF1 gene at 10q21 places it on the centromeric side of our markers. However, it remains close enough to D10S537, our most proximal marker, to be contained within the same YAC clone (6), so the probability of recombination between these loci would not exceed 1\% (6). Given that our two kindreds analyzed independently and together failed to demonstrate homozygosity by descent and shared maternal alleles for the same chromosome-10 markers used to establish linkage in other families (5), it is very unlikely that our patients have mutations in this gene. We were not surprised that our eastern Canadian families, who have English and Irish origins, do not appear to map to these loci. Our results suggest the existence of additional FHLH loci and confirm previous reports of genetic heterogeneity in this condition.

Acknowledgments. The authors thank the families for their generous cooperation. We are also indebted to Drs. Rhiannon Hughes, C. Pushpanathan, and Robert Fraser for their input and help in obtaining the pathologic tissue samples.

\section{REFERENCES}

1. Egeler RM, D'Angio GJ 1995 Medical progress: Langerhans cell histiocytosis. J Pediatr 127:1-11

2. Gencik A, Signer E, Müller HJ 1984 Genetic analysis of familial erythrophagocytic lymphohistiocytosis. Eur J Pediatr 142:248-252
3. 1999 Online Mendelian Inheritance in Man, OMIM Johns Hopkins University, Baltimore, MD MIM Number: 267700:12/20/99. World Wide Web URL: http:// www.ncbi.nlm.nih.gov/omim/

4. Ohadi M, Lalloz MRA, Sham P, Zhao J, Dearlove AM, Shiach C, Kinsey S, Rhodes M, Layton DM 1999 Localization of a gene for familial hemophagocytic lymphohistiocytosis at chromosome 9q21.3-22 by homozygosity mapping. Am J Hum Genet 64:165-171

5. Dufourcq-Lagelouse R, Jabado N, Le Deist F, Stéphan JL, Souillet G, Bruin M, Vilmer E, Schneider M, Janka G, Fischer A, de Saint Basile G 1999 Linkage of familial hemophagocytic lymphohistiocytosis to 10q21-22 and evidence for heterogeneity. Am J Hum Genet 64:172-179

6. Stepp SE, Dufourcq-Lagelouse R, Le Deist F, Bhawan S, Certain S, Mathew PA, Henter JI, Bennett M, Fischer A, de Saint Basile G, Kumar V 1999 Perforin gene defects in familial hemophagocytic lymphohistiocytosis. Science 286:1957-1959

7. Hasle H, Brandt C, Kerndrup G, Kjeldsen E, Sorensen AG 1996 Haemophagocytic lymphohistiocytosis associated with constitutional inversion of chromosome 9 . Br J Haematol 93:808-809

8. Henter JI, Elinder G, Ost A 1991 Diagnostic guidelines for hemophagocytic lymphohistiocytosis. The FHL Study Group of the Histiocyte Society. Semin Oncol $18: 29-33$

9. Madisen L, Hoar DI, Holroyd CD, Crisp M, Hodes ME 1987 DNA banking: the effects of storage of blood and isolated DNA on the integrity of DNA. Am J Med Genet 27:379-390

10. Collins A, Frezal J, Teague J, Morton NE 1996 A metric map of humans: 23,500 loci in 850 bands. Proc Natl Acad Sci USA 93:14771-14775

11. Henter JI, Elinder G, Soder O, Ost A 1991 Incidence in Sweden and clinical features of familial hemophagocytic lymphohistiocytosis. Acta Paediatr Scand 80:428-435

12. Hirst WJ, Layton DM, Singh S, Mieli-Vergani G, Chessells JM, Strobel S, Pritchard J 1994 Hemophagocytic lymphohistiocytosis. Experience at two U.K. centres. Br J Haematol 88:731-739

13. Egeler RM, Shapiro RS, Loechelt B, Filipovich AH 1996 Characteristic immune abnormalities in hemophagocytic lymphohistiocytosis. J Pediatr Hematol Oncol $18: 340-345$

14. Janka GE 1983 Familial hemophagocytic lymphohistiocytosis. Eur J Pediatr 140:221-229

15. Ambruso DR, Hays T, Zwartjes WJ, Tubergen DG, Favara BE 1980 Successful treatment of lymphohistiocytic reticulosis with phagocytosis with epipodophyllotoxin VP16-213. Cancer 45:2516-2520

16. Henter JI, Arico M, Egeler RM, Elinder G, Favara BE, Filipovich AH, Gadner H, Imashuku S, Janka-Schaub G, Komp D, Ladisch S, Webb D for the HLH Study Group of the Histiocyte Society 1997 HLH-94: treatment protocol for hemophagocytic lymphohistiocytosis. Med Pediatr Oncol 28:342-347

17. Moynihan LM, Bundey SE, Heath D, Lynn Jones E, McHale DP, Mueller RF, Markham AF, Lench NJ 1998 Autozygosity mapping, to chromosome 11q25, of a rare autosomal recessive syndrome causing histiocytosis, joint contractures, and sensorineural deafness. Am J Hum Genet 62:1123-1128

18. Mäkelä-Bengs P, Järvinen N, Vuopala K, Suomalainen A, Ignatius J, Sipilä M, Herva R, Palotie A, Peltonen L 1998 Assignment of the disease locus for lethal congenital contracture syndrome to a restricted region of chromosome $9 \mathrm{q} 34$, by genome scan using five affected individuals. Am J Hum Genet 63:506-516

19. Janka G, Imashuku S, Elinder G, Schneider M, Henter JI 1998 Infection- and malignancy-associated hemophagocytic syndromes. In: Egeler RM, D’Angio GJ (eds) Langerhans Cell Histiocytosis, Hematology/Oncology Clinics of North America. WB Saunders, Philadelphia, pp 435-444 